\title{
Management practices for male calves on Canadian dairy farms
}

\author{
D. L. Renaud, T. F. Duffield, S. J. LeBlanc, D. B. Haley, and D. F. Kelton ${ }^{1}$ \\ Department of Population Medicine, University of Guelph, Ontario, N1G 2W1 Canada
}

\begin{abstract}
Morbidity, mortality, and antimicrobial use and resistance are major concerns in the rearing of male dairy calves, so information to support disease prevention is important. The objective of this cross-sectional study was to describe management practices associated with the care of male calves during their first days of life on Canadian dairy farms. A survey was completed by dairy producers across Canada between March 1 and April 30, 2015. The survey included 192 questions covering producer background, farm characteristics, biosecurity practices, disease prevalence, calf health, animal welfare, lameness, milking hygiene, reproduction, and Internet and social media use. A total of 1,025 surveys were completed online, by telephone, or by mail, representing $9 \%$ of all dairy farms in Canada. Five percent of respondents $(n=49)$ answered that they had euthanized at least 1 male calf at birth in the previous year, and blunt force trauma was commonly used in these cases. The majority of respondents always fed colostrum to male calves; however, $9 \%(\mathrm{n}=80)$ did not always feed colostrum. Almost 40\% ( $\mathrm{n}=418)$ of respondents reported always dipping the navels of male calves, $12 \%(\mathrm{n}=123)$ vaccinated male calves, and $17 \%$ $(\mathrm{n}=180)$ did not provide the same quantity of feed to male calves as heifer calves. The care of male calves differed greatly depending on the geographical region of the respondents. However, some regional effects may be confounded by economic conditions and the logistics of marketing male dairy calves in different parts of the country. Herd size was another important variable in many aspects of the management of male calves on dairy farms. Larger herd sizes were more likely to use an appropriate method of euthanasia at birth but were less likely to always feed colostrum to their male calves or feed them the same as female calves. Familiarity with the Code of Practice for the Care and Handling of Dairy Cattle (National Farm Animal Care Council) by respondents was associated with better care of male
\end{abstract}

Received February 17, 2017.

Accepted April 7, 2017.

${ }^{1}$ Corresponding author: dkelton@uoguelph.ca calves on dairy farms. The results of this survey suggest that the treatment of male dairy calves on Canadian dairy farms varies and that there are opportunities to improve the health management of male calves on the farms of origin.

Key words: male calf, management, welfare

\section{INTRODUCTION}

Male calf health and welfare continue to be lingering issues in the dairy industry worldwide. New Zealand and Australia do not have well-established industries for raising male dairy calves, leading to the majority being transported long distances to be slaughtered within days of birth (Cave et al., 2005). Due to the effects of distance traveled and environmental stressors, male calves en route to slaughter plants experience high levels of mortality during transit (Cave et al., 2005). In Europe and North America, the majority of male dairy calves contribute to the red meat industry. The European Union has specifically addressed a significant number of public concerns regarding animal welfare through the implementation of strict animal housing and nutrition requirements for male calves being raised for meat production (European Union, 2008). The high level of importance placed on male calf welfare in the European Union has helped address some public criticism; however high levels of antimicrobial use and resistance have become major concerns for the veal industry (Pardon et al., 2014). In North America, little research on male calf health and welfare has been published over the past 2 decades. As antimicrobial resistance, mortality, and morbidity remain high among male dairy calf industries (Cook et al., 2011; Pardon et al., 2012; Winder et al., 2016), an increased focus on disease prevention needs to be a priority.

In heifer calves, many studies have highlighted the importance of neonatal calf management for both the short- and long-term survival of these calves (Weaver et al., 2000; Lombard et al., 2007; Windeyer et al., 2014). The highest risk for mortality occurs in the first $21 \mathrm{~d}$ following arrival to male calf housing (Pardon et al., 2012; Winder et al., 2016), suggesting that calf management on dairy farms also plays a key role in the prevention of mortality in male dairy calves. 
Providing a sufficient quantity of good-quality colostrum to newborn calves is an integral component of male calf management because failure of passive transfer in male calves is associated with an increased risk for many diseases (Postema and Mol, 1984; Pardon et al., 2015). Despite the known importance of feeding colostrum, failure of passive transfer is estimated to be common among male calves (Wilson et al., 2000; Schnepper, 2001; Pardon et al., 2015). It is interesting to note that a relatively recent study (Trotz-Williams et al., 2008) found no difference in failure of passive transfer between male and female calves, suggesting that poor colostrum management is widespread.

Another management practice that is used to increase host resistance to disease is the administration of vaccines. In young calves (3-8 d of age), the administration of an intranasal modified live vaccine against major viral pathogens of the bovine respiratory disease (BRD) complex has been proven to have a significant disease sparing effect, reducing clinical signs and pulmonary lesions (Xue et al., 2010). Despite the short duration of immunity induced by intranasal vaccination (Ellis et al., 2013), these vaccines may have utility in male calves raised for veal or dairy beef because pneumonia has been found to be the main reason for antimicrobial use and mortality in veal operations (Pardon et al., 2012; Lava et al., 2016).

Early-life nutrition also plays a role in increasing immune function and disease resistance. Malnourished calves have higher concentrations of blood cortisol and impaired lymphocyte function (Drackley, 2005) and take longer to recover from the effects of a Cryptosporidium parvum infection (Ollivett et al., 2012). Because male calves are often subjected to long transit times to their rearing site, during which they may experience cold or heat stress, adequate early nutrition is critical for their survival (Roland et al., 2016). The objective of this study was to describe management practices associated with the early rearing of male calves on Canadian dairy farms.

\section{MATERIALS AND METHODS}

\section{Experimental Design}

A national cross-sectional study (Belage et al., 2017) was conducted between March 1 and April 30, 2015, to collect data on management practices on Canadian dairy farms. A comprehensive questionnaire was developed by representatives from 4 veterinary schools, and questions were created to address key management and disease priorities (Bauman et al., 2016). These questions were then modified based on questions from other national surveys (USDA, 2008) and in consultation with other Canadian dairy researchers. An advisory group consisting of dairy producers, government representatives, and veterinarians was created to provide feedback on the survey content. The final questionnaire consisted of 192 questions, which were divided into producer background information, farm characteristics, biosecurity practices, disease prevalence, calf health, animal welfare, lameness, milking hygiene, reproduction, and Internet and social media use.

Human ethics approval was received from each participating university: University of Calgary (Calgary, Alberta, Canada; REB no. 14-2481), University of Guelph (Guelph, Ontario, Canada; REB no. 14DC025), Université de Montréal (Montréal, Quebec, Canada; 15-007-CERES-D), and University of Prince Edward Island (Charlottetown, Prince Edward Island, Canada; REB no. 6006095). The questionnaire was available as an online platform (Qualtrics; https://www.qualtrics. $\mathrm{com} /$ ) and as a Microsoft Word (Microsoft Corp., Redmond, WA) document for mailing out or for use as a script to allow administration over the telephone. To optimize the response rate, an incentive (\$20 gift card) was provided to the first 250 respondents.

Respondents were recruited through a letter of invitation that was mailed to every licensed dairy producer in Canada. The producer contact information was obtained through provincial milk marketing boards. To ensure that confidentiality was maintained, the marketing board provided a unique anonymous code to each producer. The letter of invitation outlined the scope of the study and presented the options for completing the survey. The methods made available were the website address for online completion of the questionnaire, a quick response code linked to the website, and a toll-free number with voicemail where requests could be made for completion over the telephone or on paper. In addition, a postage-paid reply card that contained the producer's unique code and contact information could be used to notify the researcher that the producer wished to have a paper version of the questionnaire mailed to them. In addition to the data obtained through the producer completion of the questionnaire, milk production and farm demographic data were obtained for every Canadian dairy farm from the respective provincial marketing boards. Belage et al. (2017) presents a more thorough description of the questionnaire design.

\section{Statistical Analysis}

All statistical analyses were conducted using Stata 14 (StataCorp, 2015). Data were imported from Microsoft Excel (Microsoft Corp.) into Stata 14 and checked for completeness. A causal diagram was created to evaluate the relationships between the potential exploratory 


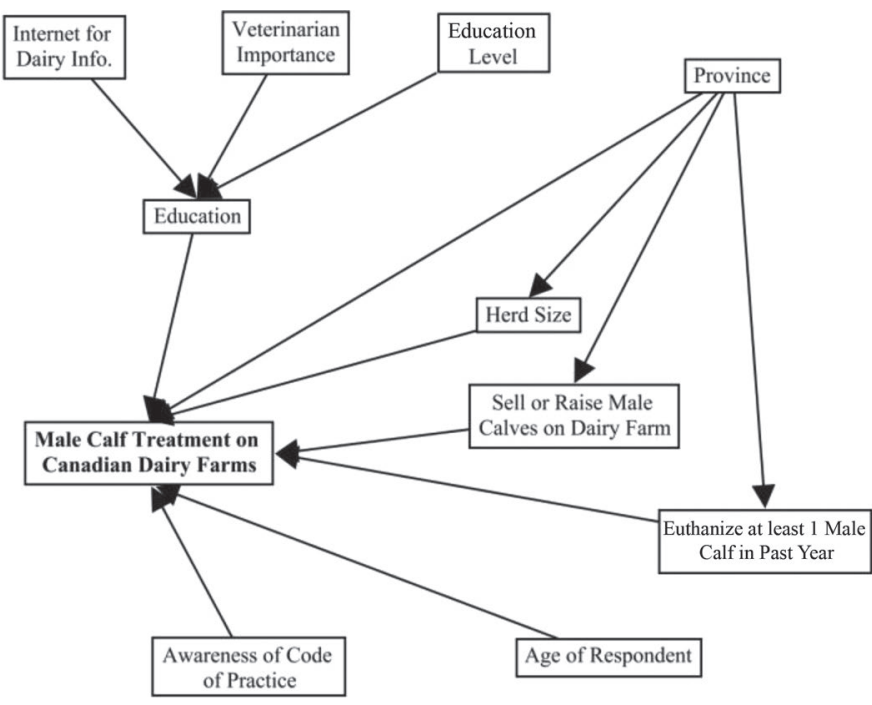

Figure 1. Causal diagram describing the relationship of measured variables to treatment of male calves on Canadian dairy farms.

variables and the outcomes of interest (Figure 1). Descriptive statistics were generated on all explanatory variables in the data set.

Six explanatory logistic regression models were created to evaluate the outcomes (1) euthanasia of male calves at birth, (2) method of male calf euthanasia at birth, (3) colostrum feeding of male calves, (4) navel dipping of male calves, (5) vaccination of male calves, and (6) feeding of male calves. The model assumption of linearity of continuous variables was assessed by plotting the logarithmic odds of the outcome against the variable. If a variable failed to meet the linearity assumption, the variable was categorized. Herd size did not meet the linearity assumption in any of the logistic models and was recategorized based on quartiles; the first, second, third, and fourth quartiles were 10 to 38,39 to 54,55 to 87 , and 88 to 888 lactating cows, respectively. Collinearity among the explanatory variables was tested using Spearman rank coefficients. If the correlation coefficient between 2 variables was $\geq 0.7$, only 1 variable was retained based on the fewest missing values, reliability of measurement, or biological plausibility. Univariable logistic regression models were constructed to screen for variables that were unconditionally associated with the outcome using a liberal $P$-value of 0.2 . Risk factors that had univariate associations $(P<0.2)$ were subsequently offered to a multivariable model through a manual backward stepwise process. Evaluation of the effect of the removed variables on the coefficients of the remaining variables was used to assess confounding. A variable was deemed to be a confounder if it was not an intervening variable based on the causal diagram and if the log odds of a significant variable in the model changed by at least 20\%. Two-way interactions between biologically important variables were evaluated and remained in the final models if significant $(P<0.05$; Dohoo et al. 2010). The model fit was assessed using Pearson and deviance chi-squared tests. Outliers were identified and evaluated using Pearson residuals and deviance residuals as well as delta betas, delta chi-squared, and delta deviance. If outliers were found, they were explored to determine the characteristics of the observations that made them outliers and to ensure that data were not erroneous.

\section{RESULTS}

\section{Sampling}

There were 11,664 unique farm codes representing active producers who were sent a letter of invitation. In total, 1,373 producers began the questionnaire and agreed to participate online; however, only 1,025 producers completed the full questionnaire. The response proportion was therefore $9 \%$, and the completion proportion was $75 \%$. Seventy-nine (8\%), $224(22 \%)$, and $722(70 \%)$ participants completed the questionnaire via telephone, on paper, and online, respectively.

\section{Respondents}

There were respondents from each of Canada's 10 provinces; the largest portion came from Quebec and Ontario (Figure 2). The respondents classified themselves as owner $(87 \%, \mathrm{n}=1,006)$, manager $(7 \%, \mathrm{n}=$ $83)$, farm worker $(2 \%, \mathrm{n}=23)$, or other $(3 \%, \mathrm{n}=39)$. Respondents placed themselves into the age categories of $\leq 29(14 \%, \mathrm{n}=163), 30$ to $49(49 \%, \mathrm{n}=564)$, and $>50$ years of age $(37 \%, \mathrm{n}=425)$. The respondents' highest level of education was high school or less for $35 \%$ $(\mathrm{n}=402)$, college or university for $63 \%(\mathrm{n}=730)$, and postgraduate education for $2 \%(\mathrm{n}=21)$. The majority of the respondents were aware of the Code of Practice for the Care and Handling of Dairy Cattle (hereafter, Code of Practice; National Farm Animal Care Council, $2009 ; 82 \%, \mathrm{n}=908)$. Of those who were aware, $39 \%$ $(\mathrm{n}=354)$ had not consulted the code in the past year, $39 \%(\mathrm{n}=349)$ had consulted it once in the past year, and $22 \%(\mathrm{n}=197)$ had consulted it more than once in the past year. The Internet was used to access dairy information by $87 \%(\mathrm{n}=911)$ of respondents.

The respondents had an average of 54 lactating cows at the time the survey was completed, which is smaller than the average Canadian herd size of 72 lactating cows (Canadian Dairy Information Center, 2016). Most of the respondents housed their cattle in tiestall barns; 
Table 1. Respondents and Canadian dairy farms (Canadian Dairy Information Center, 2016) using different housing systems

\begin{tabular}{lrrrrr}
\hline & \multicolumn{2}{c}{ Respondents } & & \multicolumn{2}{c}{ Dairy farms } \\
\cline { 2 - 3 } \cline { 5 - 6 } Housing style & $\%$ & No. & & $\%$ & No. \\
\hline Tiestall & 59 & 674 & & 71 & 5,937 \\
Freestall & 39 & 442 & & 22 & 1,878 \\
Other & 2 & 28 & & & \\
\hline
\end{tabular}

the remainder were housed in freestalls or other housing styles (Table 1). All male calves were sold within 2 wk of birth by $59 \%(\mathrm{n}=636)$ of respondents, and all male calves were raised beyond 2 wk of age by $9 \%(\mathrm{n}=$ 100) of respondents; the remaining respondents $(32 \%$, $\mathrm{n}=338$ ) reported a combination of selling and raising the male calves. A total of $63 \%(\mathrm{n}=679)$ of respondents had at least 1 animal euthanized on their farm during the previous year. When euthanizing preweaned heifers, weaned heifers, and cows, 93\% ( $\mathrm{n}=619)$ of respondents used an acceptable method of euthanasia based on the Code of Practice (gunshot, captive blot, or veterinarian) and $7 \%(\mathrm{n}=48)$ used an unacceptable method of euthanasia (blunt force trauma).

\section{Euthanizing Male Calves at Birth}

Five percent of respondents $(\mathrm{n}=49)$ answered that they had euthanized at least 1 male calf at birth during the previous 12 mo. Among these, the proportion of male calves euthanized on the farm ranged from 1 to $100 \%$, with an average of $19 \%$ being euthanized at birth. The variables unconditionally associated with euthanizing male calves at birth were geographical region, herd size, and education level.

In the final multivariable model, 3 variables were significantly associated with euthanizing at least 1 bull calf in the last year (Table 2). Herd size, geographic region, and education level were associated with being more likely to euthanize male calves at birth. No sig-

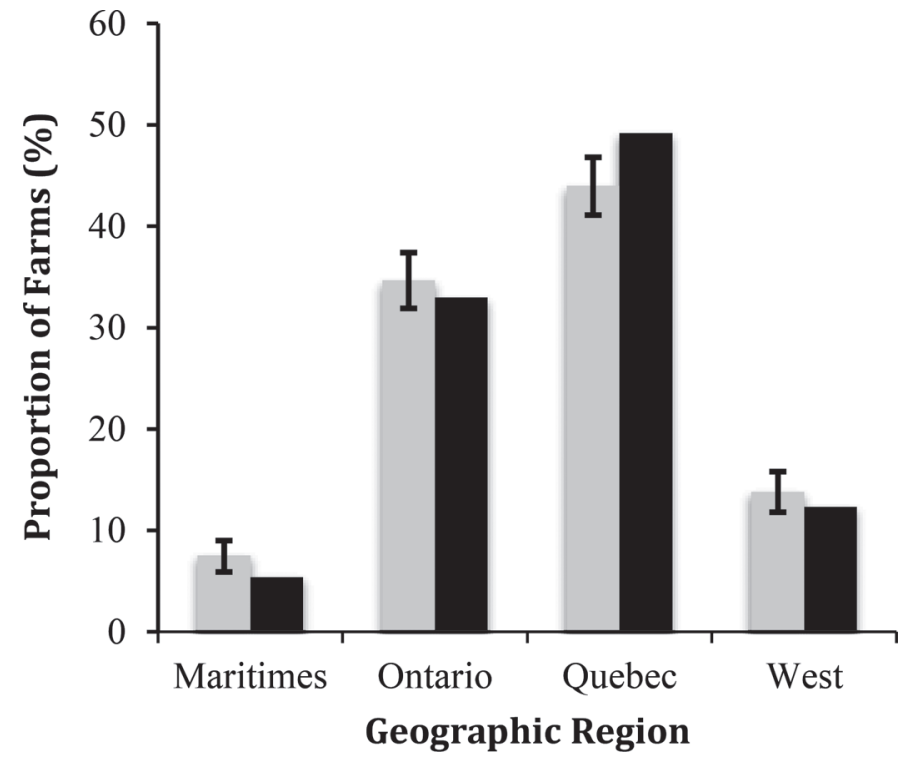

Figure 2. Proportion of respondents (gray bars; with 95\% CI) and Canadian producers (black bars; Canadian Dairy Information Center, 2016) by geographical region.

nificant interaction or confounding were present in the model. There was a single outlier that when removed changed the magnitude but not the direction of the coefficient for the postgraduate category in the education level variable. The outlier was retained in the final model because of the small number of observations in the postgraduate category.

Of those respondents who euthanized male calves at birth, $34 \%$ euthanized the calf using blunt force trauma. Univariable exact logistic regression models were built to further explore reasons for euthanizing with blunt force trauma. Being located in the province of Quebec [odds ratio $(\mathbf{O R})=20.6(2.5-\infty), P<0.01$ ] was significantly associated with using blunt force trauma at birth. Respondents were less likely to report using blunt force trauma if they reported using an acceptable method of euthanasia on cows and heifers $[\mathrm{OR}=0.01$

Table 2. Results of a multivariable logistic regression model of euthanizing at least 1 neonatal male dairy calf in the previous year as reported by respondents to a survey of Canadian dairy farmers

\begin{tabular}{llcccc}
\hline Variable & Intercept & No. & Odds ratio & $95 \%$ CI & $P$-value \\
\hline Geographical region & Ontario & 320 & Referent & & \\
& Quebec & 416 & 1.28 & $0.53-3.11$ & 0.59 \\
& West & 119 & 1.35 & $0.46-3.98$ & 0.58 \\
Education level & Atlantic & 67 & 6.43 & $2.47-16.76$ & $<0.001$ \\
& High school & 298 & Referent & & \\
College or university & 605 & 1.97 & $0.82-4.71$ & 0.13 \\
Herd size & Postgraduate & 19 & 6.66 & $1.43-30.92$ & 0.02 \\
& $10-38$ & 227 & Referent & & \\
& $39-54$ & 226 & 1.94 & $0.52-7.14$ & 0.32 \\
& $55-87$ & 238 & 2.78 & $0.84-9.22$ & 0.095 \\
& $88-888$ & 231 & 5.31 & $1.66-17.00$ & $<0.001$ \\
\hline
\end{tabular}


Table 3. Results of a multivariable logistic regression model of always feeding colostrum to male dairy calves as reported by respondents to a survey of Canadian dairy farmers

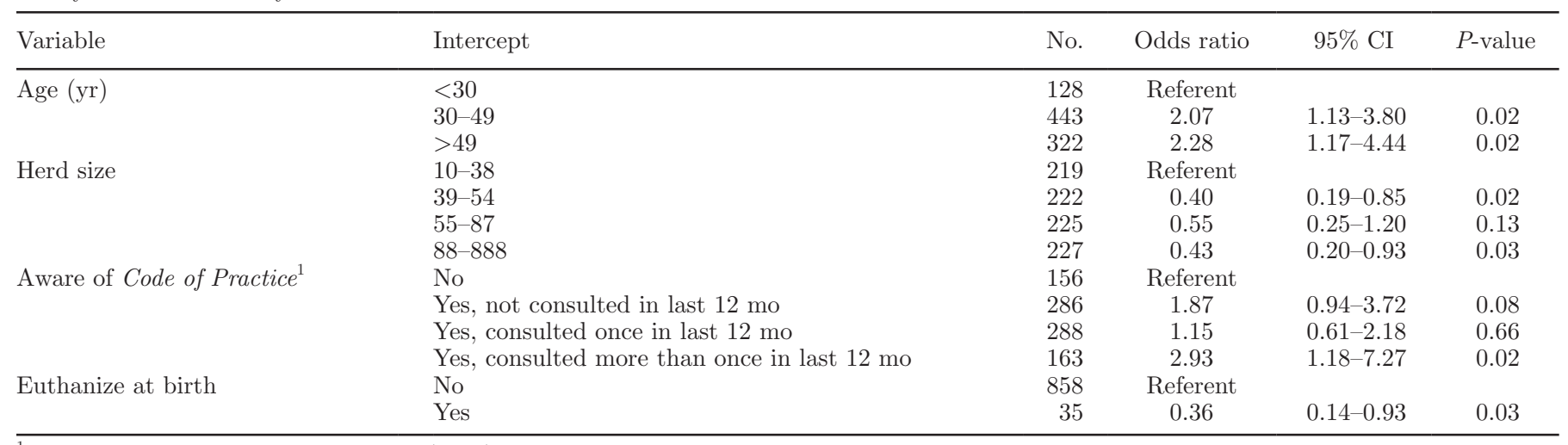

${ }^{1}$ National Farm Animal Care Council (2009).

(0.00-0.06), $P \leq 0.001]$, milking 80 to 133 cows $[\mathrm{OR}=$ 0.09 (0.00-0.80), $P \leq 0.05]$, or consulting the Code of Practice more than once in the past year $[\mathrm{OR}=0.11$ (0.00-1.04), $P=0.05]$.

\section{Colostrum Management}

Ninety-one percent of producers responded that they always feed colostrum to male calves. The variables unconditionally associated with always feeding colostrum were age, herd size, euthanizing at birth, awareness of the Code of Practice, and the reported importance of the veterinarian as a source of dairy health and management information.

In the final multivariable model for always feeding colostrum to male calves, 4 variables were significant (Table 3). Older respondents and those who had consulted the Code of Practice more than once in the previous 12 mo were more likely to always feed colostrum to male calves. Respondents with medium to larger herds and those who reported euthanizing at least 1 male calf at birth were less likely to feed colostrum. A single outlier was identified; it did not affect the magnitude and direction of the coefficients in the model and thus was not removed.

\section{Navel Dipping}

Almost 40\% $(\mathrm{n}=418)$ of respondents reported that they always navel dipped male calves. The variables unconditionally associated with always navel dipping were geographical region, euthanizing bull calves at birth, awareness of the Code of Practice, use of the Internet as a source of dairy information, the veterinarian being reported as a very important source of information, and herd size.

In the multivariable model, 3 variables were significant (Table 4). Navel dipping varied by region, use of the Code of Practice, and use of the Internet for dairy information. Eight outliers that shared the same covariate pattern were identified. When the observations responsible for this covariate pattern were removed, the magnitude and direction of the coefficients in the model did not change, and thus the observations were left in the model.

Table 4. Results of a multivariable logistic regression model of always navel dipping male dairy calves as reported by respondents to a survey of Canadian dairy farmers

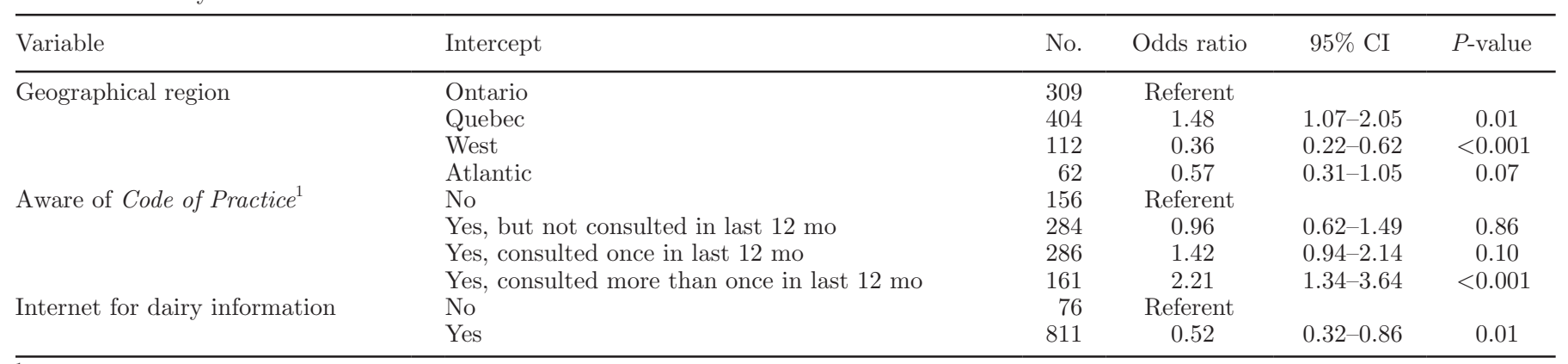

\footnotetext{
${ }^{1}$ National Farm Animal Care Council (2009).
} 
Table 5. Results of a multivariable logistic regression model of always vaccinating male dairy calves as reported by respondents to a survey of Canadian dairy farmers

\begin{tabular}{|c|c|c|c|c|c|}
\hline Variable & Intercept & No. & Odds ratio & $95 \% \mathrm{CI}$ & $P$-value \\
\hline \multirow{2}{*}{ Geographical region } & Quebec & 405 & 0.42 & $0.23-0.77$ & 0.01 \\
\hline & Atlantic & 61 & 0.92 & $0.37-2.28$ & 0.86 \\
\hline \multirow[t]{2}{*}{ Raise or sell } & Sell $<50 \%$ & 99 & Referent & & \\
\hline & Sell $>50 \%$ & 785 & 0.11 & $0.07-0.19$ & $<0.001$ \\
\hline Veterinarian importance & Not a very important source & 191 & Referent & & \\
\hline
\end{tabular}

\section{Vaccination}

Approximately $12 \%(\mathrm{n}=123)$ of respondents indicated that male calves were always vaccinated. Geographical region, education category, selling greater than 50\% of male calves before 2 wk of age, veterinarians being a very important source of information, and herd size were offered to a multivariable model.

In the final multivariable model, region, age of sale of male calves, and reporting the veterinarian as an important source of information were associated with vaccination of bull calves (Table 5). One outlier was identified but did not change the magnitude or direction of the coefficients and thus was kept in the final model.

\section{Feeding}

Eighty-three percent $(\mathrm{n}=880)$ of respondents reported always feeding male calves the same or more as heifer calves of the same age. The variables offered to the multivariable model were geographical region, age category, euthanizing at birth, awareness of the Code of Practice, use of the Internet as a source of dairy information, and herd size.

In the final multivariable model, region, practicing euthanasia at birth, and herd size were associated with male calf feeding practices (Table 6). Five identified outliers were represented by a single covariate pat- tern. When the outliers were removed from the model, the magnitude but not the direction of the variable "euthanized at birth" changed. However, these outliers remained in the model because of the small number of respondents who euthanized at birth.

\section{DISCUSSION}

On Canadian dairy farms there exists a large amount of variation regarding the management of male calves in early life. The majority of respondents reported that male calves always received colostrum and were always fed the same as or more than heifer calves. A minority of respondents always navel dipped male calves, vaccinated male calves, or euthanized male calves at birth. To our knowledge, this is the first study to describe management practices associated with male calves on Canadian dairy farms.

A small number of respondents reported that they had euthanized at least 1 male calf at birth within the previous year. A major factor that could affect the decision to euthanize is economics. There is significant variability both within and between years in the price paid to Canadian producers for male calves (Figure 3). With an uncertain economic climate, some producers may decide to euthanize male calves because of the inability to generate a profit once the calf is housed and fed for several days before sale. In the Atlantic provinces, especially Newfoundland, a lack of accessi-

Table 6. Results of a multivariable logistic regression model of always feeding male dairy calves the same as or more than heifer calves of the same age as reported by respondents to a survey of Canadian dairy farmers

\begin{tabular}{llcccc}
\hline Variable & Intercept & No. & Odds ratio & $95 \%$ CI & $P$-value \\
\hline Geographical region & Ontario & 310 & Referent & & \\
& Quebec & 404 & 0.29 & $0.18-0.45$ & $<0.001$ \\
& West & 114 & 1.5 & $0.66-3.43$ & 0.34 \\
Euthanize at birth & Atlantic & 62 & 0.65 & $0.29-1.50$ & 0.32 \\
& No & 855 & Referent & & \\
Herd size & Yes & 35 & 0.43 & $0.19-0.96$ & 0.04 \\
& $10-38$ & 217 & Referent & & $0.37-1.04$ \\
& $39-54$ & 222 & 0.62 & $0.32-0.92$ & 0.02 \\
& $55-88$ & 228 & 0.55 & $0.33-1.09$ & 0.09 \\
\hline
\end{tabular}




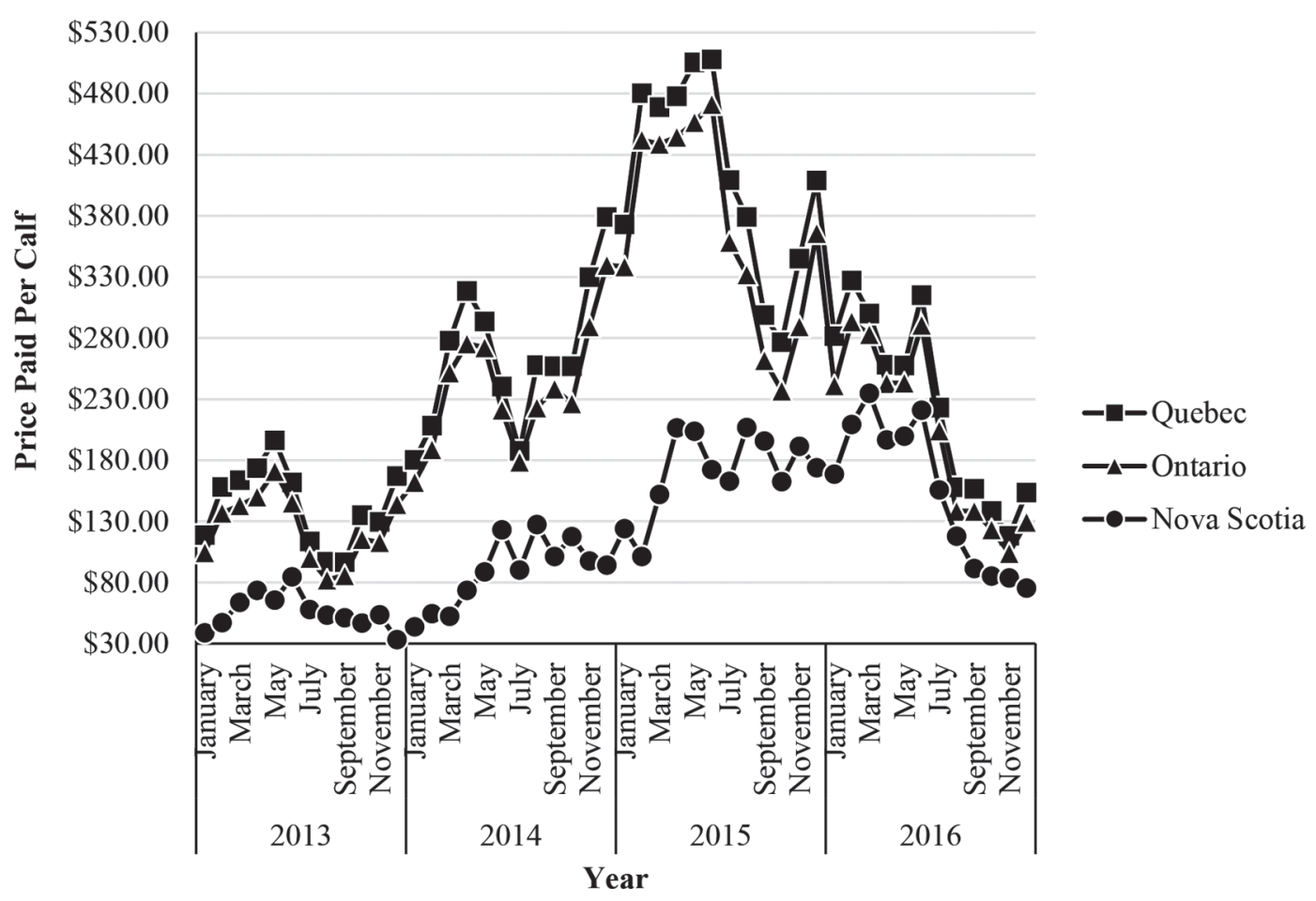

Figure 3. Price paid per male dairy calf $<125 \mathrm{lb}(<57 \mathrm{~kg})$ at Quebec, Ontario, and Nova Scotia auction facilities by year (Atlantic Stockyards Limited, 2016; Beef Farmers of Ontario, 2016; Les Producteurs de Bovins du Quebec, 2016).

bility to facilities that either raise male calves or market fully grown calves further compounds the economic challenges faced by dairy producers making decisions about male calf euthanasia. Because respondents in the Atlantic provinces had much higher odds of euthanasia at birth, it is likely that this economic factor explains this practice in this region of Canada. The inability to account for this economic factor is a limitation of this study and is likely a major confounder of the regional effects.

Several other reasons could explain euthanizing calves at birth. Dystocia can inflict severe injury and pain, resulting in poor vitality in the newborn calf (Murray and Leslie, 2013). Because male dairy calves commonly experience dystocia (Olson et al., 2009), it is likely that some of the respondents euthanized male calves due to their poor chance of survival. With dystocia occurring in more than $10 \%$ of calvings in North America (Mee, 2008), larger herds have a greater probability of having difficult calvings, resulting in more calves with poor vitality requiring euthanasia. This may be the reason why larger herds were associated with euthanizing at least 1 male calf at birth. Respondents with a postgraduate education reported a greater likelihood of euthanizing bull calves at birth, which was surprising. The type of degree was not specified; therefore, they could have been veterinarians or animal science graduates who recognized that calves born with poorer vitality would likely have a difficult time recovering.

A disturbing result was the reported use of blunt force trauma as a method of euthanasia for male dairy calves at birth $(\mathrm{n}=16)$ and female dairy animals $(\mathrm{n}=$ 48). It is not an acceptable method of euthanasia for neonatal calves because the anatomical features make it difficult to achieve immediate destruction of brain tissue and because it is challenging to apply this method consistently (Leary et al., 2013). This method of euthanasia is also not deemed acceptable in the Canadian Code of Practice. Quebec farms reported a much higher rate of performing this method of euthanasia at birth. The reasons why this practice differs by geographical region need to be evaluated to eliminate the use of this method. Larger farms tended to euthanize male calves at birth with an appropriate method; thus, it is possible that they euthanize more animals and might be more confident with using other methods of euthanasia such as gunshot. As the Canadian Code of Practice explicitly describes the proper methods of euthanasia (National Farm Animal Care Council, 2009), it is not surprising that consulting the code more frequently was associated with lower odds of euthanizing male calves at birth with blunt force trauma. It remains unclear whether the respondents who read the code are more welfare conscious and thus sought out the correct method of 
euthanasia to ensure rapid loss of consciousness and death or whether they were just more compliant with regulations. Regardless, these findings need to be further explored to ensure that producers are educated on alternative and appropriate humane methods of euthanasia so that the appropriate interventions are used on all farms.

Despite overwhelming evidence surrounding the importance of colostrum management and feeding, $9 \%$ of respondents answered that they did not always feed colostrum to male calves. It could be speculated that this is an underestimation of the number who do not feed colostrum to male calves because of the presence of desirability bias. It is difficult to comment on the favorability of feeding colostrum to male calves because no information was collected on the quality, quantity, quickness, and cleanliness of colostrum management. Shivley et al. (2016) reported that a higher proportion of producers in the United States fed male calves colostrum; only $4 \%$ of male calves did not receive colostrum. They also discovered many differences that existed between female and male calves regarding colostrum management. Male calves received a smaller volume of colostrum, had delayed colostrum feeding, and were left to suckle the colostrum from their dam more commonly than female calves. A study conducted in Canada also showed differential treatment of male calves (Fecteau et al., 2002), where male calves were more likely than female calves to receive colostrum with higher bacterial counts.

Several variables were associated with feeding colostrum to male calves. Being in an older age category was positively associated with always feeding colostrum. One possibility is that some of the younger respondents may not fully understand the importance of colostrum or that producers may deem male calves to be a low priority due to the fluctuating prices paid for them. The latter theory could also be used to explain why larger farms were less likely to always feed colostrum to male calves. The Canadian Code of Practice states that calves must receive at least $4 \mathrm{~L}$ of good-quality colostrum within $12 \mathrm{~h}$ of birth, with the first meal occurring as soon as possible and no more than $6 \mathrm{~h}$ after birth (National Farm Animal Care Council, 2009). Hence, it is not unexpected that consulting the code more frequently was associated with always feeding male calves colostrum. Both theories presented earlier could also apply here in that those consulting the code ensure that they meet the requirements or are more welfare conscious and recognize the importance of feeding colostrum. All of these factors need to be further explored to ensure that male calves always receive colostrum to help improve male calf health and welfare.
Navel dipping is a relatively common practice; almost $40 \%$ of respondents reported that they dipped the navels of all bull calves. However, there is a surprising paucity of data in the literature to support its use. Grover and Gooden (2011) demonstrated that using a navel dip to control omphalitis might provide some benefit; however, the use of historical controls in that study makes interpreting the findings difficult. Other studies have shown that navel dipping is associated with an increase in the risk of pneumonia (Waltner-Toews et al., 1986; Windeyer et al., 2014). Both of these studies concluded that this topic requires additional research. In the current study, differences in navel dipping were found with regards to geographical region. It could be speculated that these differences are attributable to the availability of educational resources for producers in those regions. The Internet can be a great resource for dairy information but can also provide incorrect and misleading information. Although considerable anecdotal information regarding the importance of navel dipping is available on the Internet, it was surprising to find that producers who were more likely to access the Internet were less likely to navel dip. One of the recommended practices of the Code of Practice is to dip calf navels in disinfectant as soon as possible after birth. This statement could have influenced producers who have read the Code of Practice to apply navel dip to all calves.

Very few respondents vaccinated their male calves. The lack of vaccination was especially true if the respondents were from Quebec and sold their male calves before 2 wk of age. However, if the respondents viewed their veterinarian as an important source of information, they were more likely to vaccinate their male calves. As previously stated, evidence supports the intranasal vaccination of young calves and its disease-sparing effect against viral pathogens in the BRD complex. A model that has been used successfully in beef production to help reduce the incidence of BRD is for cow-calf producers to vaccinate their animals 2 to 3 wk before the animals enter the feedlot (Cusack et al., 2003). This model potentially could be used in male dairy calves to control BRD, but a premium needs to be paid to the dairy producers who implement this practice.

Although the majority of respondents reported always feeding male calves the same as or more than female calves of the same age, a large number of respondents $(\mathrm{n}=179)$ did not always feed male calves the same. This was an anticipated result because many male calves enter rearing facilities with a lack of subcutaneous fat covering their frame or even an emaciated appearance (Wilson et al., 2000). Poorer nutrition of male calves compared with female calves was also sub- 
jected to regional variation: farms in Quebec showed greater likelihood of differential feeding of male calves. Having euthanized a male calf at birth was also associated with reduced nutrition. Because lower weight at arrival is one factor that is a significant predictor of mortality in veal operations (Winder et al., 2016), nutrition and age at transport need to be further explored to reduce the levels of mortality occurring on veal and dairy beef farms.

\section{CONCLUSIONS}

The major findings of this survey demonstrate that the standard of care for male calves needs to be enhanced on some Canadian dairy farms. The issues of colostrum management and early nutrition need to be further explored to help reduce morbidity and mortality with the ultimate goal of improving male calf welfare. An interesting finding was that the care of male calves differed greatly depending on the geographical region of the respondents. We hypothesize that some of the regional effects we found may be confounded by different economic conditions and logistics of marketing male dairy calves in different parts of the country. Another theme that continued through the study was larger farms having differences in welfare practices: they were more likely to use an appropriate method for euthanizing male calves at birth but were also associated with being less likely to always feed colostrum and not feeding male calves the same as female calves. As the trend toward larger farms continues, it is important to further explore reasons for these practices. The consultation of the Canadian Code of Practice by respondents was consistently associated with improved care of male calves on dairy farms. Because the Code of Practice provides producers with valuable information that affects dairy cattle welfare, efforts need to be made to increase its effect in regions where it is not known or used.

\section{ACKNOWLEDGMENTS}

The authors thank all of the participating producers for completing the National Dairy Study in 2015. These data were collected as part of the National Dairy Study, funded by Dairy Farmers of Canada and Agriculture and Agri-Food Canada through the Dairy Research Cluster 2 Program. The first author (D.L.R.) was also supported by Grober Inc. (Cambridge, ON, Canada), Veal Farmers of Ontario (Guelph, ON, Canada), Dairy Farmers of Ontario (Mississauga, ON, Canada), the Ontario Ministry of Agriculture, Food and Rural Affairs, and the Ontario Veterinary College (University of Guelph).

\section{REFERENCES}

Atlantic Stockyards Limited. 2016. Market reports. Accessed Apr. 1, 2017. http://www.atlanticstockyards.com/marketreports.html.

Bauman, C. A., H. W. Barkema, J. Dubuc, G. P. Keefe, and D. F. Kelton. 2016. Identifying management and disease priorities of Canadian dairy industry stakeholders. J. Dairy Sci. 99:10194-10203.

Beef Farmers of Ontario. 2016. Individual auction market reports. Accessed Jan. 16, 2017. http://www.ontariobeef.com/markets/ market-reports.aspx.

Belage, E., S. Dufour, C. Bauman, A. Jones-Bitton, and D. F. Kelton. 2017. The Canadian National Dairy Study 2015-Adoption of milking practices in Canadian dairy herds. J. Dairy Sci. 100:3839-3849.

Canadian Dairy Information Center. 2016. Overview of Canadian dairy industry at the farm. Accessed Jan. 5, 2017. http://www. dairyinfo.gc.ca/index_e.php?s1=dff-fcil\&s $2=$ farm-ferme\&s $3=\mathrm{nb}$.

Cave, J. G., A. Callinan, and W. Woonton. 2005. Mortalities in bobby calves associated with long distance transport. Aust. Vet. J. 83:8284. https://doi.org/10.1111/j.1751-0813.2005.tb12203.x.

Cook, A., R. J. Reid-Smith, R. J. Irwin, S. A. McEwen, V. Young, K. Butt, and C. Ribble. 2011. Antimicrobial resistance in Escherichia coli isolated from retail milk-fed veal meat from southern Ontario, Canada. J. Food Prot. 74:1328-1333. https://doi. org/10.4315/0362-028X.JFP-10-495.

Cusack, P. M., N. McMeniman, and I. Lean. 2003. The medicine and epidemiology of bovine respiratory disease in feedlots. Aust. Vet. J. 81:480-487. https://doi.org/10.1111/j.1751-0813.2003.tb13367.x.

Dohoo, I., W. Martin, and H. Stryhn. 2010. Model building strategies. Pages 365-398 in Veterinary Epidemiological Research. 2nd ed. S. M. McPike, ed. VER Inc., Charlottetown, Prince Edward Island, Canada.

Drackley, J. 2005. Does early growth affect subsequent health and performance of heifers? Advances Dairy Technol. 17:189-205.

Ellis, J. A., S. P. Gow, S. Mahan, and R. Leyh. 2013. Duration of immunity to experimental infection with bovine respiratory syncytial virus following intranasal vaccination of young passively immune calves. J. Am. Vet. Med. Assoc. 243:1602-1608. https://doi. org/10.2460/javma.243.11.1602.

European Union. 2008. Council directive: Laying down minimum standards for protection of calves. Off. J. Eur. Union 10:7-13.

Fecteau, G., P. Baillargeon, R. Higgins, J. Paré, and M. Fortin. 2002. Bacterial contamination of colostrum fed to newborn calves in Québec dairy herds. Can. Vet. J. 43:523-527.

Grover, W., and S. Gooden. 2011. Efficacy of a new navel dip to prevent umbilical infection in dairy calves. Bovine Pract. 45:70-77.

Lava, M., G. Schüpbach-Regula, A. Steiner, and M. Meylan. 2016. Antimicrobial drug use and risk factors associated with treatment incidence and mortality in Swiss veal calves reared under improved welfare conditions. Prev. Vet. Med. 126:121-130. https://doi. org/10.1016/j.prevetmed.2016.02.002.

Leary, S., W. Underwood, and R. Anthony. 2013. AVMA Guidelines for the Euthanasia of Animals. 8th ed. American Veterinary Medical Association, Schaumburg, IL.

Les Producteurs de Bovins du Quebec. 2016. Cull cattle and bob calves weekly report. Accessed Apr. 1, 2017. http://bovin.qc.ca/ en/price-info/cull-cattle-and-bob-calves/weekly.

Lombard, J. E., F. B. Garry, S. M. Tomlinson, and L. P. Garber. 2007. Impacts of dystocia on health and survival of dairy calves. J. Dairy Sci. 90:1751-1760. https://doi.org/10.3168/jds.2006-295.

Mee, J. F. 2008. Prevalence and risk factors for dystocia in dairy cattle: A review. Vet. J. 176:93-101. https://doi.org/10.1016/j. tvjl.2007.12.032.

Murray, C. F., and K. E. Leslie. 2013. Newborn calf vitality: Risk factors, characteristics, assessment, resulting outcomes and strategies for improvement. Vet. J. 198:322-328. https://doi.org/10.1016/j. tvj1.2013.06.007.

National Farm Animal Care Council. 2009. Code of Practice for the Care and Handling of Dairy Cattle. National Farm Animal Care Council, Lacombe, Alberta, Canada.

Ollivett, T. L., D. V. Nydam, T. C. Linden, D. D. Bowman, and M. E. Van Amburgh. 2012. Effect of nutritional plane on health 
and performance in dairy calves after experimental infection with Cryptosporidium parvum. J. Am. Vet. Med. Assoc. 241:1514-1520. https://doi.org/10.2460/javma.241.11.1514.

Olson, K. M., B. G. Cassell, A. J. McAllister, and S. P. Washburn. 2009. Dystocia, stillbirth, gestation length, and birth weight in Holstein, Jersey, and reciprocal crosses from a planned experiment. J. Dairy Sci. 92:6167-6175. https://doi.org/10.3168/jds.2009-2260.

Pardon, B., J. Alliët, R. Boone, S. Roelandt, B. Valgaeren, and P. Deprez. 2015. Prediction of respiratory disease and diarrhea in veal calves based on immunoglobulin levels and the serostatus for respiratory pathogens measured at arrival. Prev. Vet. Med. 120:169-176. https://doi.org/10.1016/j.prevetmed.2015.04.009.

Pardon, B., B. Catry, R. Boone, H. Theys, K. De Bleecker, J. Dewulf, and P. Deprez. 2014. Characteristics and challenges of the modern Belgian veal industry. Vlaams Diergen. Tijds. 83:155-163.

Pardon, B., K. De Bleecker, M. Hostens, J. Callens, J. Dewulf, and P. Deprez. 2012. Longitudinal study on morbidity and mortality in white veal calves in Belgium. BMC Vet. Res. 8:26. https://doi. org/10.1186/1746-6148-8-26.

Postema, H. J., and J. Mol. 1984. Risk of disease in veal calves: Relationships between colostrum-management, serum immunoglobulin levels and risk of disease. Zentralbl. Veterinarmed. A 31:751-762. https://doi.org/10.1111/j.1439-0442.1984.tb01334.x.

Roland, L., M. Drillich, D. Klein-Jöbstl, and M. Iwersen. 2016. Invited review: Influence of climatic conditions on the development, performance, and health of calves. J. Dairy Sci. 99:2438-2452. https://doi.org/10.3168/jds.2015-9901.

Schnepper, R. L. 2001. Veal calf TLC. J. Am. Vet. Med. Assoc. 219:1389-1391.

Shivley, C. B., N. Urie, and J. E. Lombard. 2016. Management of dairy bull calves on U.S. dairy operations. J. Anim. Sci. 94(Suppl. 5):581. (Abstr.) https://doi.org/10.2527/jam2016-1210.

StataCorp. 2015. Stata Statistical Software: Release 14. StataCorp LP, College Station, TX.

Trotz-Williams, L. A., K. E. Leslie, and A. S. Peregrine. 2008. Passive immunity in Ontario dairy calves and investigation of its associa- tion with calf management practices. J. Dairy Sci. 91:3840-3849. https://doi.org/10.3168/jds.2007-0898.

USDA. 2008. Dairy 2007: Part II: Changes in the U.S. dairy cattle industry, 1991-2007. USDA, Animal and Plant Health Inspection Service, Veterinary Services, and National Animal Health Monitoring System, Fort Collins, CO.

Waltner-Toews, D., S. W. Martin, and A. H. Meek. 1986. Dairy calf management, morbidity and mortality in Ontario Holstein herds. III. Association of management with morbidity. Prev. Vet. Med. 4:137-158. https://doi.org/10.1016/0167-5877(86)90019-x.

Weaver, D. M., J. W. Tyler, D. C. VanMetre, D. E. Hostetler, and G. M. Barrington. 2000. Passive transfer of colostral immunoglobulins in calves. J. Vet. Intern. Med. 14:569-577.

Wilson, L. L., J. L. Smith, D. L. Smith, D. L. Swanson, T. R. Drake, D. R. Wolfgang, and E. F. Wheeler. 2000. Characteristics of veal calves upon arrival, at 28 and 84 days, and at end of the production cycle. J. Dairy Sci. 83:843-854. https://doi.org/10.3168/jds. S0022-0302(00)74948-4.

Winder, C. B., D. F. Kelton, and T. F. Duffield. 2016. Mortality risk factors for calves entering a multi-location white veal farm in Ontario, Canada. J. Dairy Sci. 99:10174-10181. https://doi. org/10.3168/jds.2016-11345.

Windeyer, M. C., K. E. Leslie, S. M. Godden, D. C. Hodgins, K. D. Lissemore, and S. J. LeBlanc. 2014. Factors associated with morbidity, mortality, and growth of dairy heifer calves up to 3 months of age. Prev. Vet. Med. 113:231-240. https://doi.org/10.1016/j. prevetmed.2013.10.019.

Xue, W., J. Ellis, D. Mattick, L. Smith, R. Brady, and E. Trigo. 2010. Immunogenicity of a modified-live virus vaccine against bovine viral diarrhea virus types 1 and 2, infectious bovine rhinotracheitis virus, bovine parainfluenza-3 virus, and bovine respiratory syncytial virus when administered intranasally in young calves. Vaccine 28:3784-3792. https://doi.org/10.1016/j.vaccine.2010.03.043. 